\title{
Analisis Ketelitian Geometric Citra Pleiades 1A untuk Pembuatan Peta Dasar Lahan Pertanian (Studi Kasus: Kecamatan Socah, Kabupaten Bangkalan)
}

\author{
Andreas Kelvin Pujianto, Bangun Muljo Sukojo, Husnul Hidayat \\ Jurusan Teknik Geomatika, Fakultas Teknik Sipil dan Perencanaan, Institut Teknologi Sepuluh \\ Nopember (ITS) \\ Jl. Arief Rahman Hakim, Surabaya 60111 Indonesia \\ e-mail: bangunms@gmail.com
}

\begin{abstract}
Abstrak-Penggunaan citra satelit resolusi tinggi lebih tepat dan akurat dibanding citra satelit resolusi rendah. Pada saat ini, beberapa satelit dapat menghasilkan citra dengan resolusi spasial kurang dari $1 \mathrm{~m}$. Selain itu, salah satu keuntungan dari data citra satelit resolusi tinggi untuk deteksi dan inventarisasi sumber daya alam adalah setiap lembar (scene) citra ini mencakup wilayah yang sangat luas yaitu sekitar 60-180 km2 (360.000-3.240.000 ha) [5]. Interpretasi visual pada citra Pleiades 1A dan survei lapangan telah membuktikan bahwa mayoritas daerah Kecamatan Socah memiliki tutupan lahan berupa lahan pertanian yang lebih banyak dibandingkan dengan kecamatan lainnya di Kabupaten Bangkalan. Alasan tersebut menjadikan Kecamatan Socah sebagai lokasi penelitian. Proses rektifikasi citra menggunakan koordinat titik horizontal $(\mathrm{X}, \mathrm{Y})$ dari Ground Control Point (GCP) yang didapatkan dari pengukuran lapangan menggunakan GPS geodetik dengan metode static dengan lama pengukuran 45 menit tiap baseline. Sedangkan untuk uji ketelitian citra menggunakan pengukuran titik Independent Control Point (ICP) yang didapatkan dari pengukuran GPS geodetik dengan metode static dengan lama pengukuran 15 menit. Nilai Root Mean Square Error (RMSE) titik ICP dari transformasi affine sebesar $0,645 \mathrm{~m}$, sedangkan polynomial orde2 sebesar $0,533 \mathrm{~m}$. Masing-masing nilai RMSE titik ICP kemudian dikalikan dengan koefisien Circular Error 90\% (CE90) dari Perka BIG no. 15 tahun 2014 maka didapatkan nilai ketelitian geometric sebesar $0,979 \mathrm{~m}$ pada affine dan $0,809 \mathrm{~m}$ pada polynomial orde-2. Hasil ketelitian geometric dari kedua metode transformasi menunjukkan nilai $\leq 1 \mathrm{~m}$, sehingga citra Pleiades 1A memenuhi syarat untuk dijadikan sebagai peta dasar skala 1:5.000 dengan kategori kelas 1.
\end{abstract}

Kata Kunci- GCP, ICP, Koreksi Geometric, Pleiades 1A, RMSE

\section{PENDAHULUAN}

$\mathrm{K}$ EMAJUAN teknologi di bidang penginderaan jauh (inderaja) memberikan banyak pilihan citra satelit yang dapat digunakan untuk memantau kondisi permukaan Bumi. Saat ini, citra satelit resolusi tinggi sudah banyak digunakan dalam inderaja. Penggunaan citra satelit resolusi tinggi lebih tepat dan akurat dibanding citra satelit resolusi rendah. Selain itu, salah satu keuntungan dari data citra satelit resolusi tinggi untuk deteksi dan inventarisasi sumber daya lahan pertanian adalah setiap lembar (scene) citra ini mencakup wilayah yang sangat luas yaitu sekitar $60-180 \mathrm{~km}^{2}(360.000$ 3.240.000 ha) [5]. Dengan mengamati daerah yang sangat luas sekaligus, beserta keadaan lahan yang mencakup topografi atau relief, pertumbuhan tanaman atau vegetasi dan fenomena alam yang terekam dalam citra memberi peluang untuk mengamati, mempelajari pengaruh iklim, vegetasi, litologi dan topografi terhadap penyebaran sumber daya lahan dan lahan pertanian [5]. Penyebaran kondisi serta perubahan lahan pertanian tidak dapat diketahui secara pasti tanpa bantuan teknologi yang lebih maju. Laju pertumbuhan penduduk yang tinggi (1,6\% per tahun) ikut andil menyebabkan perubahan penggunaan lahan dengan cepat [2], sehingga inventarisasi dan pemantauan penggunaan lahan yang dilaksanakan secara terestris (ground base method) tidak dapat mengikuti laju perubahannya.

Karena kemajuan teknologi yang sangat pesat dalam inderaja, manusia dapat melakukan penelitian tanpa harus turun langsung ke lapangan seperti pengukuran terestris dengan luasan yang sangat besar, namun semua itu dapat digantikan hanya dengan menganalisa citra satelit. Citra satelit resolusi tinggi harus dikoreksi secara radiometrik dan geometric sebelum digunakan lebih lanjut. Salah satu metode untuk mendapat koordinat terkoreksi pada citra adalah dengan proses koreksi geometric. Koreksi geometric merupakan suatu proses yang bertujuan untuk melakukan transformasi data dari suatu sistem proyeksi dengan menggunakan suatu transformasi geometri sehingga citra mempunyai sifat-sifat peta yang sama dalam bentuk skala dan proyeksi. Koreksi tersebut untuk memberi koreksi spasial akibat kesalahan geometric yang dialami citra.

Untuk meminimalisir kesalahan geometric (pergesaran nilai koordinat) akibat sudut perekaman, perlu digunakan data tambahan yaitu koordinat GCP (Ground Control Point) dan ICP (Independent Control Point) sehingga memenuhi akurasi absolut dan relatif sesuai spesifikasi [6]. Setiap piksel pada citra diposisikan ulang sesuai koordinat sebenarnya dengan acuan horizontal dari data GPS (Global Potitioning System).

\section{METODOLOGI PENELITIAN}

\section{A. Lokasi Penelitian}

Lokasi penelitian ini adalah Kecamatan Socah, Kabupaten Bangkalan yang terletak pada $6^{\circ} 51$ ' $39^{\prime \prime}-7^{\circ} 11$ ' 39” LS, $112^{\circ} 40^{\prime} 06^{\prime \prime}-113^{\circ} 08^{\prime} 04^{\prime \prime}$ BT. Secara administratif, sebelah utara Kecamatan Socah berbatasan dengan Kecamatan Bangkalan, sebelah timur berbatsan dengan Kecamatan Burneh dan Tragah, sebelah barat dengan Selat Madura, 
sedangkan sebelah timur dengan Kecamatan Kamal dan Labang.

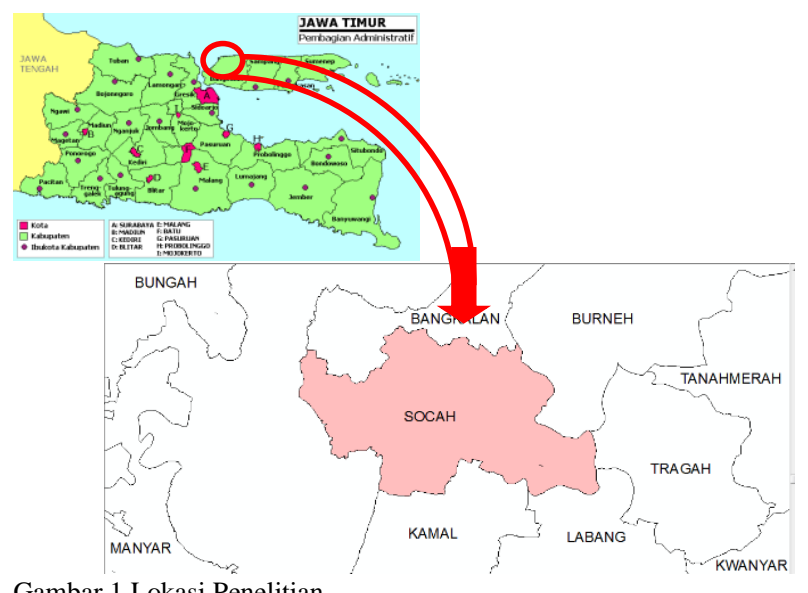

Gambar 1 Lokasi Penelitian

(sumber: : id.wikipedia.org dan shp.file Batas Wilayah Kecamatan (BIG))

\section{B. Data dan Peralatan}

1) Data

Data yang digunakan dalam penelitian ini yaitu:

a. Data citra Pleiades 1A wilayah Kab. Bangkalan resolusi spasial 0,5 meter, direkam pada tanggal 28 Agustus 2015.

b. Data pengukuran GCP dan ICP di lapangan dengan menggunakan GPS geodetik.

2) Peralatan

Peralatan yang digunakan dalam penelitian ini yaitu:

a. Perangkat lunak (software) yang digunakan dalam Peneliaan ini tugas akhir ini antara lain:

i. Windows 7

ii. Microsoft Office 2013

iii. ArcGIS 10.1

b. Peralatan lain yang digunakan untuk Survei lapangan :

i. Kamera

ii. 3 set GPS geodetik Top-Con HiperPro

iii. Alat tulis

\section{Tahap Pengolahan Data}

Berikut adalah flowchart pengolahan data dari penelitian ini:

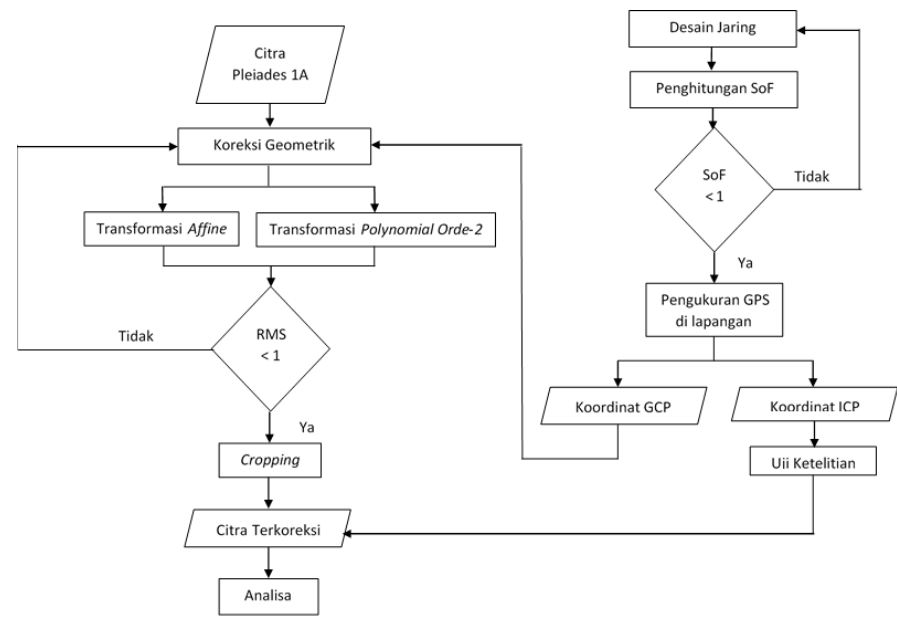

Gambar 2 Flowchart Pengolahan Data
Penjelasan tahap pengolahan data tersebut adalah: a. Data

Pada proses pengolahan, yang diperlukan antara lain adalah data citra Pleiades, dan data titik kontrol (GCP dan ICP).

b. Desain Jaring

Sebelum pengolahan lebih lanjut, diperlukan desain jaring dengan cara meletakkan titik GCP dan ICP secara merata di area studi.

c. Perhitungan SoF

Perhitungan SoF perlu dilakukan untuk mengetahui kekuatan desain jaring dari sebaran (Ground Control Point) GCP yang ada pada citra. Besar nilai SoF harus kurang dari satu atau lebih baik jika mendekati nol. Apabila nilai SoF lebih dari satu, maka desain jaring dan perhitungan SoF harus diulang.

d. Pengamatan GPS

Koordinat titik kontrol (GCP) sebanyak 7 titik diukur dengan pengamatan GPS menggunakan metode rapid static dengan lama pengamatan 45 menit setiap baseline. Sedangkan ICP 12 titik dan diukur selama 15 menit.

e. Koreksi Geometric

Koreksi geometric dilakukan untuk memperbaiki nilai spasial dari citra Pleiades. Koreksi geometric yang dilakukan meliputi dua metode yaitu affine dan polynomial orde-2.

f. RMS error

Pengecekan RMS error dimaksudkan agar nilai RMSE kurang dari satu atau lebih baik jika mendekati nol. Apabila nilai RMSE lebih dari satu, maka proses koreksi geometric harus diulang.

g. Uji Ketelitian

Uji ketelitian didapat dari perhitungan RMSE titik ICP dikalikan dengan nilai ketelitian geometric berdasarkan Perka BIG Nomor 15 tahun 2014.

h. Cropping

Cropping adalah proses pemotongan citra yang disesuaikan dengan area penelitian. Hasil cropping akan mempercepat waktu pemrosesan tahap selanjutnya.

i. Citra Terkoreksi

Pada tahap ini, citra sudah terkoreksi secara geometric, dan dapat digunakan untuk proses selanjutnya seperti pembuatan peta citra skala 1:5000 atau skala lebih kecil.

j. Analisa

Dari hasil perhitungan RMSE dengan kedua metode transformasi dan nilai RMSE per titik pada citra dapat dilakukan analisa. Selain itu, nilai RMSE tersebut dikalikan dengan koefisien ketelitian untuk mengetahui tingkat kelayakan citra sebagai peta dasar skala tertentu.

\section{HASIL DAN PEMBAHASAN}

\section{A. Hasil Pan-Sharpening}

Pan-Sharpening adalah proses penggabungan band pankromatik dan band multispektral pada citra satelit. Proses ini menghasilkan citra yang memiliki ketajaman spasial dan spektral sekaligus yang nantinya akan mempermudah interpretasi citra dan penentuan titik kontrol. Proses PanSharpening citra Pleiades dilakukan dengan metode GramSchmidt Spectral Sharpening. Proses ini menghasilkan 4 band multispektral yang masing-masing memiliki ketajaman piksel sebesar 0,5 m. Berikut adalah hasil Pan-Sharpening 
citra Pleiades dengan tampilan RGB (Red: band_1, Green: band_2, Blue: band_3).
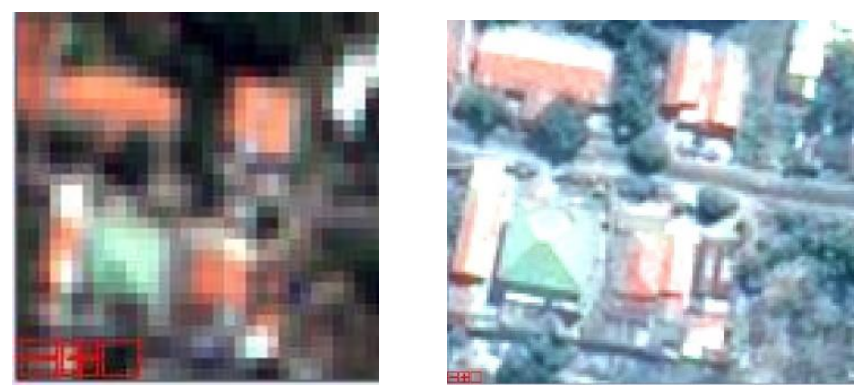

Gambar 3 Gambar Citra Satelit Pleiades 1A Sebelum Pan-Sharpening (kiri), sesudah Pan-Sharpening (kanan)

\section{Penentuan Letak Titik Kontrol}

Titik Kontrol Tanah (GCP) idealnya diletakkan pada jalan, sungai, garis pantai, teluk, tanjung, atau kenampakan pada permukaan Bumi lainnya yang dapat dikenali dengan kemungkinan perubahan yang relatif lambat/tetap [4]. Penentuan titik GCP diusahakan menyebar pada posisi terluar dari citra yang akan dilakukan rektifikasi. Penentuan lokasi GCP sebaiknya melalui interpretasi terhadap citra yang akan direktifikasi, agar mudah diidentifikasi di citra.

Dalam penelitian ini, digunakan 7 titik GCP dan 12 titik ICP yang didesain pada citra Pleiades dengan tampilan sebagai berikut:

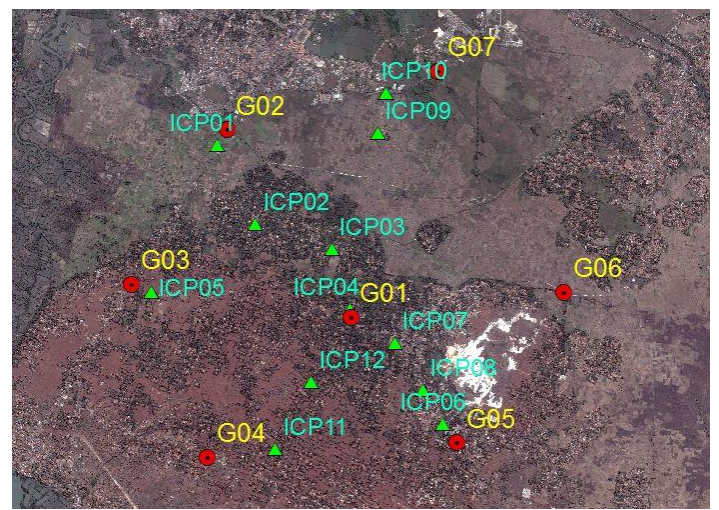

Gambar 4 Penentuan Titik GCP dan ICP Pada Citra Satelit Pleiades 1A

\section{Kekuatan Jaring}

Setelah menentukan posisi titik (GCP), diperlukan adanya perhitungan kekuatan jaring/Strength of Figure (SoF) untuk mengetahui seberapa baik penentuan posisi titik GCP dan jumlah baseline yang sudah dibuat pada desain jaring. Semakin kecil bilangan faktor kekuatan jaring, maka akan semakin baik konfigurasi jaring yang dibuat dan sebaliknya [1].

Perhitungan nilai faktor kekuatan jaring ini menggunakan metode kuadrat terkecil (least square) dengan perhitungan sebagai berikut :

$$
\begin{aligned}
& >\text { Jumlah titik }(\mathrm{S})=7 \\
& >\mathrm{Jumlah} \text { baseline }(\mathrm{N})=12 \\
& >\mathrm{n}=\mathrm{N} \times 3=12 \times 3=36 \\
& >\mathrm{u}=\mathrm{S} \times 3=7 \times 3=21 \\
& >\mathrm{n}=36-21=15 \\
& \text { BesarSoF }=\frac{\text { Trace }\left(A^{T} A\right)^{-1}}{\text { jumlahParameter }}
\end{aligned}
$$

$=0,123$

Nilai SoF sebesar 0,123 menunjukkan kekuatan jaring yang kuat karena mendekati nol.

\section{Koordinat Titik GCP dan ICP Hasil Pengukuran GPS}

Koordinat titik kontrol $(\mathrm{X}, \mathrm{Y})$ GCP dan ICP didapatkan dari pengukuran di lapangan dengan menggunakan alat GPS geodetik, di mana koordinat ini digunakan untuk koreksi geometric dan uji ketelitian geometric. Berikut ini merupakan daftar koordinat titik kontrol yang digunakan:

Tabel 1

Daftar Koordinat Titik Kontrol GCP

\begin{tabular}{cccc}
\hline \hline \multirow{2}{*}{ No. } & Nama & \multicolumn{2}{c}{ Titik Kontrol } \\
\cline { 3 - 4 } & Titik & $\mathbf{X ~ ( m )}$ & Y (m) \\
\hline 1. & G01 & 692790,382 & 9217377,097 \\
2. & G02 & 691152,016 & 9219851,711 \\
3. & G03 & 689884,391 & 9217811,100 \\
4. & G04 & 690900,993 & 9215513,836 \\
5. & G05 & 694202,883 & 9215710,714 \\
6. & G06 & 695606,230 & 9217706,671 \\
7. & G07 & 693954,707 & 9220622,346 \\
\hline \hline
\end{tabular}

Tabel 2

Daftar Koordinat Citra Pleiades 1A

\begin{tabular}{cccc}
\hline \hline \multirow{2}{*}{ No. } & Nama & \multicolumn{2}{c}{ Pleiades 1A } \\
\cline { 3 - 4 } & Titik & X (piksel) & Y (piksel) \\
\hline 1. & G01 & 20.045 & -19.640 \\
2. & G02 & 16.903 & -15.141 \\
3. & G03 & 14.608 & -19.174 \\
4. & G04 & -23.415 & -23.415 \\
5. & G05 & 22.734 & -22.632 \\
6. & G06 & 25.289 & -18.665 \\
7. & G07 & 22.109 & -13.329 \\
\hline
\end{tabular}

Tabel 3

Daftar Koordinat Titik ICP

\begin{tabular}{cccc}
\hline \hline \multirow{2}{*}{ No. } & Nama & & \multicolumn{2}{c}{ Titik ICP } \\
\cline { 4 - 4 } Titik & X $(\mathbf{m})$ & Y $(\mathbf{m})$ \\
\hline 1. & ICP 01 & 692539,9880 & 9218272,4820 \\
2. & ICP 02 & 693261,5300 & 9220330,3100 \\
3. & ICP 03 & 693150,6450 & 9219809,0760 \\
4. & ICP 04 & 691532,1760 & 9218600,6370 \\
5. & ICP 05 & 690147,0200 & 9217707,0580 \\
6. & ICP 06 & 692780,3580 & 9217477,4300 \\
7. & ICP 07 & 693371,9610 & 9217032,4470 \\
8. & ICP 08 & 693747,5430 & 9216406,2130 \\
9. & ICP 09 & 694015,9900 & 9215961,2080 \\
10. & ICP 10 & 692270,1650 & 9216513,1440 \\
11. & ICP 11 & 691793,5710 & 9215620,8980 \\
12. & ICP 12 & 691025,7580 & 9219645,5860 \\
\hline \hline
\end{tabular}

\section{Perhitungan Root Mean Square Error (RMSE)}

Hasil tranformasi koordinat citra ke dalam koordinat titik GCP dan ICP menghasilkan residu. Residu merupakan selisih antara koordinat yang dianggap benar dalam hal ini yaitu koordinat dari pengukuran GPS dengan koordinat hasil

\begin{tabular}{|c|c|c|c|c|}
\hline \multirow{2}{*}{ No. } & \multirow{2}{*}{$\begin{array}{c}\text { Nama } \\
\text { Titik }\end{array}$} & \multicolumn{3}{|c|}{ "Pleiades 1A } \\
\hline & & Residual X & Residual Y & Residual \\
\hline 1. & G01 & $-0,718$ & 0,326 & 0,788 \\
\hline 2. & G02 & 0,532 & 0,145 & 0,551 \\
\hline 3. & G03 & $-0,317$ & $-0,262$ & 0,412 \\
\hline
\end{tabular}
transformasi dari citra Pleiades 1A dengan metode affine dan polynomial orde-2. Dari hasil residu tersebut, dapat dihitung besar nilai RMSE sebagai berikut:

Tabel 4

Daftar RMSE Titik GCP dengan Metode Affine 


\begin{tabular}{ccccc}
\hline \hline 4. & G04 & $-0,013$ & 0,036 & 0,039 \\
5. & G05 & 0,908 & $-0,071$ & 0,911 \\
6. & G06 & $-0,054$ & $-0,093$ & 0,551 \\
7. & G07 & 0,151 & $-0,082$ & 0,172 \\
8. & & Total RMSE & & $\mathbf{0 , 5 6 8 ~ m}$ \\
\hline
\end{tabular}

Tabel 5

Daftar RMSE Titik GCP dengan Metode Polynomial orde-2

\begin{tabular}{ccccc}
\hline \hline \multirow{2}{*}{ No. } & Nama & \multicolumn{3}{c}{ Pleiades 1A } \\
\cline { 3 - 5 } & Titik & Residual $\mathbf{X}$ & Residual $\mathbf{Y}$ & Residual \\
\hline 1. & G01 & 0,004 & $-0,008$ & 0,009 \\
2. & G02 & $-0,061$ & 0,112 & 0,128 \\
3. & G03 & 0,062 & $-0,114$ & 0,130 \\
4. & G04 & $-0,048$ & 0,088 & 0,100 \\
5. & G05 & 0,046 & $-0,084$ & 0,095 \\
6. & G06 & $-0,423$ & 0,077 & 0,088 \\
7. & G07 & 0,039 & $-0,071$ & 0,081 \\
8. & & Total RMSE & & $\mathbf{0 , 0 9 8} \mathbf{~ m}$ \\
\hline
\end{tabular}

Tabel 6

Daftar Koordinat Titik ICP (GPS dan interpretasi) dari Metode Affine

\begin{tabular}{cccccc}
\hline \multirow{2}{*}{ No } & \multirow{2}{*}{ Nama } & \multicolumn{2}{c}{ ICP $($ GPS $)$} & \multicolumn{2}{c}{ ICP (Interpretasi) } \\
\cline { 3 - 6 } & Titik & $\mathbf{X}(\mathbf{m})$ & $\mathbf{Y}(\mathbf{m})$ & $\mathbf{X}(\mathbf{m})$ & $\mathbf{Y}(\mathbf{m})$ \\
\hline 1 & ICP 01 & 692539,988 & 9218272,482 & 692539.760 & 9218272.997 \\
2 & ICP 02 & 693261,530 & 9220330,310 & 693261.279 & 9220330.826 \\
3 & ICP 03 & 693150,645 & 9219809,076 & 693150.195 & 9219809.769 \\
4 & ICP 04 & 691532,176 & 9218600,637 & 691531.686 & 9218601.234 \\
5 & ICP 05 & 690147,020 & 9217707,058 & 690146.755 & 9217707.487 \\
6 & ICP 06 & 692780,358 & 9217477,430 & 692780.060 & 9217477.237 \\
7 & ICP 07 & 693371,961 & 9217032,447 & 693371.512 & 9217032.985 \\
8 & ICP 08 & 693747,543 & 9216406,213 & 693748.027 & 9216405.552 \\
9 & ICP 09 & 694015,990 & 9215961,208 & 694015.434 & 9215960.973 \\
10 & ICP 10 & 692270,165 & 9216513,144 & 692269.731 & 9216513.495 \\
11 & ICP 11 & 691793,571 & 9215620,898 & 691793.026 & 9215621.378 \\
12 & ICP 12 & 691025,758 & 9219645,586 & 691025.476 & 9219645.088 \\
\hline \hline
\end{tabular}

Tabel 7

Daftar RMSE Titik ICP dari Metode Affine

\begin{tabular}{|c|c|c|c|c|}
\hline \multirow{2}{*}{ No. } & \multirow{2}{*}{$\begin{array}{c}\text { Nama } \\
\text { Titik }\end{array}$} & \multicolumn{3}{|c|}{ Pleiades 1-A } \\
\hline & & Residual X & Residual $\mathrm{Y}$ & Residual \\
\hline 1 & ICP 01 & 0.052 & 0.265 & 0.317 \\
\hline 2 & ICP 02 & 0.063 & 0.266 & 0.329 \\
\hline 3 & ICP 03 & 0.203 & 0.480 & 0.683 \\
\hline 4 & ICP 04 & 0.240 & 0.356 & 0.596 \\
\hline 5 & ICP 05 & 0.070 & 0.184 & 0.254 \\
\hline 6 & ICP 06 & 0.089 & 0.037 & 0.126 \\
\hline 7 & ICP 07 & 0.202 & 0.290 & 0.492 \\
\hline 8 & ICP 08 & 0.234 & 0.436 & 0.670 \\
\hline 9 & ICP 09 & 0.310 & 0.055 & 0.365 \\
\hline 10 & ICP 10 & 0.188 & 0.124 & 0.312 \\
\hline 11 & ICP 11 & 0.297 & 0.230 & 0.527 \\
\hline 12 & ICP 12 & 0.079 & 0.248 & 0.328 \\
\hline 13 & & Total RMS & & $0,645 \mathrm{~m}$ \\
\hline
\end{tabular}

Tabel 8

Daftar Koordinat Titik ICP (GPS dan interpretasi) dari Metode Polynomial orde-2

\begin{tabular}{cccccc}
\hline \hline \multirow{2}{*}{ No } & \multirow{2}{*}{$\begin{array}{c}\text { Nama } \\
\text { Titik }\end{array}$} & \multicolumn{2}{c}{ ICP (GPS) } & \multicolumn{2}{c}{ ICP (Interpretasi) } \\
\cline { 3 - 6 } & $\mathbf{X}(\mathbf{m})$ & $\mathbf{Y ~ ( m )}$ & $\mathbf{X}(\mathbf{m})$ & $\mathbf{Y}(\mathbf{m})$ \\
\hline 1 & ICP 01 & 692539,988 & 9218272,482 & 692540,551 & 9218272,145 \\
2 & ICP 02 & 693261,530 & 9220330,310 & 693261,187 & 9220330,456 \\
3 & ICP 03 & 693150,645 & 9219809,076 & 693149,989 & 9219809,683 \\
4 & ICP 04 & 691532,176 & 9218600,637 & 691531,462 & 9218601,002 \\
5 & ICP 05 & 690147,020 & 9217707,058 & 690146,332 & 9217707,216 \\
6 & ICP 06 & 692780,358 & 9217477,430 & 692780,397 & 9217477,227 \\
7 & ICP 07 & 693371,961 & 9217032,447 & 693371,482 & 9217032,139 \\
\hline \hline
\end{tabular}

\begin{tabular}{cccccc}
\hline \hline 8 & ICP 08 & 693747,543 & 9216406,213 & 693747,577 & 9216406,126 \\
9 & ICP 09 & 694015,990 & 9215961,208 & 694015,617 & 9215961,370 \\
10 & ICP 10 & 692270,165 & 9216513,144 & 692269,679 & 9216513,126 \\
11 & ICP 11 & 691793,571 & 9215620,898 & 691793,742 & 9215621,091 \\
12 & ICP 12 & 691025,758 & 9219645,586 & 691025,535 & 9219645,668 \\
\hline \hline
\end{tabular}

Tabel 9

Daftar RMSE Titik ICP dari Metode Polynomial orde-2

\begin{tabular}{ccccc}
\hline \multirow{2}{*}{ No. } & \multirow{2}{*}{ Nama } & \multicolumn{3}{c}{ Pleiades 1-A } \\
\cline { 3 - 5 } & Titik & Residual $\mathbf{X}$ & Residual $\mathbf{Y}$ & Residual \\
\hline 1 & ICP 01 & 0,317 & 0.114 & 0,430 \\
2 & ICP 02 & 0,118 & 0.026 & 0,140 \\
3 & ICP 03 & 0,431 & 0.368 & 0,799 \\
4 & ICP 04 & 0,510 & 0.133 & 0,643 \\
5 & ICP 05 & 0,473 & 0.025 & 0,498 \\
6 & ICP 06 & 0,002 & 0.041 & 0,043 \\
7 & ICP 07 & 0,230 & 0.095 & 0,325 \\
8 & ICP 08 & 0,001 & 0.008 & 0,009 \\
9 & ICP 09 & 0,139 & 0.026 & 0,165 \\
10 & ICP 10 & 0,236 & 0.003 & 0,236 \\
11 & ICP 11 & 0,029 & 0.037 & 0,066 \\
12 & ICP 12 & 0,050 & 0.007 & 0,056 \\
13 & & Total RMSE & \\
\hline \hline
\end{tabular}

Dari hasil perhitungan transformasi koordinat citra Pleiades 1A dengan metode affine dan polynomial orde-2, dapat diketahui bahwa nilai RMSE yang dihasilkan oleh polynomial orde-2 lebih kecil dibandingkan dengan affine. Hal ini dikarenakan metode polynomial orde-2 merupakan pengembangan dari metode affine [7].

Untuk mengetahui perbedaan besar nilai RMSE setiap metode pada citra Pleiades 1-A dapat dilihat pada gambar 4 .

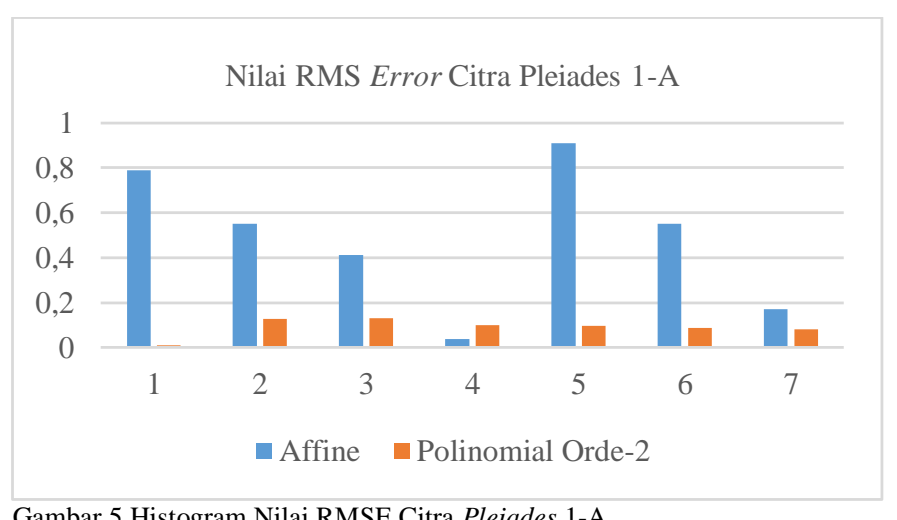

Gambar 5 Histogram Nilai RMSE Citra Pleiades 1-A

Menurut Perka BIG Nomor 15 Tahun 2014 [3], ketentuan ketelitian geometri horizontal setiap peta adalah sebagai berikut:

Tabel 10 Ketelitian Geometri Peta [3]

\begin{tabular}{ccccc}
\hline \hline & & \multicolumn{3}{c}{ Ketelitian Peta RBI } \\
\cline { 3 - 5 } No & Skala & Kelas 1 & Kelas 2 & Kelas 3 \\
\cline { 3 - 5 } & & $\begin{array}{c}\text { Horizontal } \\
(\text { CE90 dalam m) }\end{array}$ & $\begin{array}{c}\text { Horizontal } \\
(\text { CE90 dalam m })\end{array}$ & $\begin{array}{c}\text { Horizontal } \\
(\text { CE90 dalam m) }\end{array}$ \\
\hline 1. & $1: 5.000$ & 1 & 1,5 & 2,5 \\
2. & $1: 2.500$ & 0,5 & 0,75 & 1,25 \\
3. & $1: 1.000$ & 0,2 & 0,3 & 0,5 \\
\hline \hline
\end{tabular}

Circular Error 90\% (CE90) adalah ukuran ketelitian geometric horizontal yang didefinisikan sebagai radius 
lingkaran yang menunjukkan bahwa $90 \%$ kesalahan atau perbedaan posisi horizontal objek di peta dengan posisi yang dianggap sebenarnya tidak lebih besar dari radius tersebut. Nilai CE90 kemudian dihitung berdasarkan rumus [3]:

$$
\text { CE90 }=1,5175 \times \text { RMSE }
$$

Berdasarkan perhitungan perkalian nilai RMSE titik ICP kedua metode transformasi dengan koefisien ketelitian diperoleh nilai ketelitian horizontal pada citra Pleiades 1A dengan metode affine sebesar $1,5175 \times 0,645 \mathrm{~m}=0,979 \mathrm{~m}$ dan dengan metode polynomial orde- 2 sebesar $1,5175 \times 0,533 \mathrm{~m}=$ 0,809 m. Nilai ketelitian geometric dari kedua metode transformasi menunjukkan nilai $\leq 1 \mathrm{~m}$, sehingga citra Pleiades 1A memenuhi syarat untuk dijadikan sebagai peta dasar skala 1:5.000 dengan kategori kelas 1.

\section{KESIMPULAN DAN SARAN}

Kesimpulan yang dapat diambil dari penelitian ini adalah sebagai berikut.

a. Dari hasil perhitungan transformasi koordinat metode affine dan polynomial orde-2, nilai RMSE GCP sebesar 0,568 m, RMSE ICP sebesar 0,533 m dari metode affine. Sedangkan pada metode polynomial orde-2, nilai RMSE GCP sebesar 0,098 $\mathrm{m}$ dan RMSE ICP sebesar 0,645 m. Metode polynomial orde-2 menghasilkan nilai RMSE yang lebih baik dari pada affine karena polynomial orde-2 merupakan pengembangan dari metode affine.

b. Untuk kelayakan citra sebagai peta dasar, citra Pleiades 1A memenuhi syarat untuk pembuatan peta dasar lahan pertanian hingga kategori kelas 1 untuk skala 1:5.000. Hal ini dibuktikan dengan nilai ketelitian geometric dari CE90 oleh kedua metode tersebut yaitu $\leq 1 \mathrm{~m}$.

Adapun saran untuk penelitian ini dan penelitian selanjutnya adalah:

a. Dalam pengukuran titik GCP metode jaring, sebaiknyamenggunakan titik pengikat dari BIG contohnya seperti titik SRGI 2013 yang letaknya terdekat dari lokasi penelitian.

b. Sebaiknya dalam penelitian selanjutnya dalam koreksi geometric citra resolusi tinggi, metode transformasi yang disarankan adalah polynomial orde-2 agar RMSE yang didapat semakin baik, yaitu mendekati nol.

c. Dalam melakukan interpretasi citra secara visual, objek bangunan yang memiliki atap berbahan tanah liat cukup sulit untuk dibedakan dengan permukaan tanah. Sebaiknya dalam menentukan GCP maupun ICP, objek yang digunakan adalah bangunan yang memiliki warna atap yang mencolok, atau objek lain yang mempunyai kondisi serupa.

\section{PENUTUP}

Penulis menyadari bahwa jurnal ini masih banyak kekurangan baik dalam penulisan maupun dari segi isi, karena itu penulis sangat mengharapkan saran dan kritik yang membangun guna perbaikan penelitian ini kelak. Akhir kata, penulis menyampaikan banyak terima kasih semoga jurnal ini dapat bermanfaat untuk mahasiswa Teknik Geomatika FTSPITS.

\section{DAFTAR PUSTAKA}

[1] Abidin, HZ, 2000. Penentuan Posisi dengan GPS dan Aplikasinya. Jakarta: Pradnya Paramita.

[2] Adimihardja A., Wahyunto dan Rizatus Shofiyati. 2004. Gagasan Pengendalian Konversi Lahan Sawah Dalam Rangka Peningkatan Ketahanan Pangan Nasional. Prosiding Seminar: Multi Fungsi Pertanian dan Konservasi Sumber daya Lahan, di Bogor,18 Desember 2003 dan 7 Januari 2004 halaman 47-64. Puslitbang Tanah dan Agroklimat. Bogor.

[3] BIG. 2014. Peraturan Kepala Badan Informasi Geospasial Nomor 15 Tahun 2014 Tentang Pedoman Teknis Ketelitian Peta Dasar. Cibinong: Kepala BIG.

[4] [Badan Informasi Geospasial, 2016. Modul Validasi Peta Rencana Tata Ruang. Cibinong, Sekretariat BIG.

[5] Pusat Penelitian Tanah dan Agroklimat. 2000. Sumber daya Lahan Indonesia dan Pengelolaannya. Puslit. Tanah dan Agroklimat. Bogor.

[6] Sukmayadi, D. 2014. Citra Tegak Satelit Resolusi Tinggi Strategi Pemenuhan Kebutuhan Survei dan Pemetaan Skala Besar Secara Cepat <URL:http://www.bakosurtanal.go.id__diakses pada tanggal 19 Januari 2015 pukul 22.51

[7] Mohammed, N.Z. \& Eiman Eisa. "The Effect of Polynomial Order on Georeferencing Remote Sensing Images." International Journal of Engineering and Innovative Technology (IJEIT), 2013: Volume 2, Issue 8. 